\title{
Peran Gamifikasi E-Commerce Untuk Mendukung Ekonomi Kreatif
}

\author{
Qurotul Aini $^{1}$, Mukti Budiarto ${ }^{2}$, Aulia Edliyanti ${ }^{3}$ \\ ${ }^{1}$ Program Studi Sistem Informasi Universitas Raharja, ${ }^{2}$ Program Studi Teknik Informatika \\ Universitas Raharja, ${ }^{3}$ Program Studi Komputerisasi Akuntansi Universitas Raharja \\ Email : "1 aini@ raharja.info, ${ }^{2}$ mukti@ raharja.info, ${ }^{3}$ aulia.edliyanti@ raharja.info
}

\begin{abstract}
In accordance with Presidential Decree Number 142 of 2018 on Economic Development Master Plan 2018-2025 National Creative that serve as the foundation in developing a creative economy that supports the national policy on "Making Indonesia 4.0", however, the current problem is the lack of contribution and the role of students in developing economic digitization. creative and marked by the lack of renewal of the Entrepreneurship course. Another problem is that there are still many agencies that have not been able to provide a website-based $e$ commerce container to accommodate student research results. With this problem, an ecommerce gamification-based student creative economy is utilized which aims to increase student interest in digitizing a creative economy and increase the number of quality scientific publications. Stages of research methods Gameplay e-commerce such as playing a game each user gets a level from the category of product purchased, of course, each level has its own features that make users interested in the privileges of each level.
\end{abstract}

Keywords: Creative economy, digitalization, e-commerce, gamification

\section{Pendahuluan}

Era revolusi industri 4.0_menjadikan ekonomi kreatif salah satu pilihan industri baru yang mulai banyak diminati para pengusaha pemula [1]. Ditandai dengan berbagai inovasi dan kreativitas yang masing masingnya mempunyai nilai tambah [2]. Model ekonomi baru dicirikan oleh kegiatan ekonomi yang didasarkan pada ide, kreativitas pengetahuan serta inovasi sebagai dasar kegiatan.[3][4]

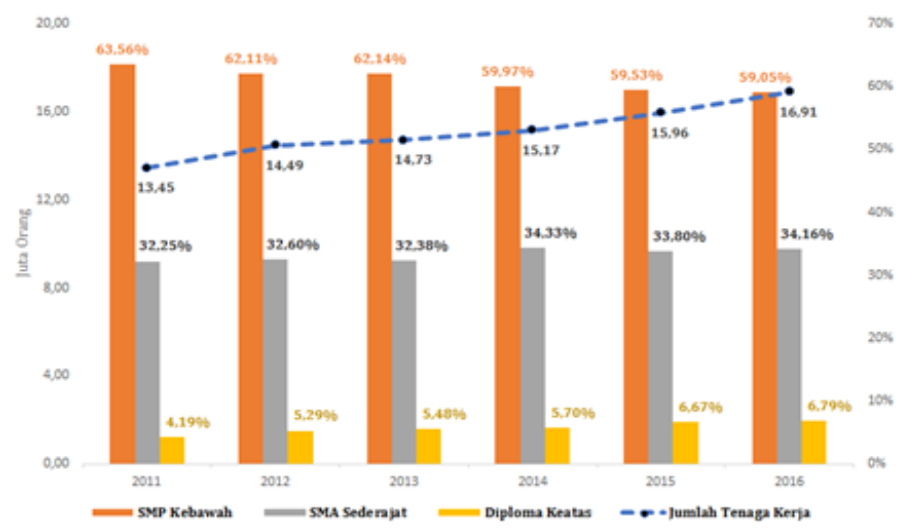

Gambar 1. Grafik Pertumbuhan Ekonomi Kreatif

Pertumbuhan ekonomi kreatif mengalami peningkatan dan memberikan kontribusi sebesar $7,44 \%$ bagi perekonomian nasional. Untuk mengembangkan ekonomi kreatif di era digital 
diperlukan strategi dan pengembangan bisnis untuk menjangkau pasar global[5]. Tidak dipungkiri era digitalisasi mempengaruhi dan mendukung munculnya para pelaku ekonomi kreatif yang mulai tertarik pada industri kreatif.[6][7]

Namun permasalahan yang dihadapi yaitu keikutsertaan mahasiswa terhadap digitalisasi ekonomi kreatif [8][9]. selain itu di Indonesia masih banyak instansi yang belum mampu menyediakan wadah e-commerce website- berdasarkan untuk menampung produk penelitian siswa[10][11]. Dari permasalahan tersebut dibuat digitalisasi dalam ekonomi kreatif mahasiswa berbasis gamifikasi e-commerce[12][13]. Diharapkan ekonomi kreatif dapat meningkatkan minat mahasiswa sehingga dapat menghasilkan produk penelitian dengan kreativitas[14][15]. Dengan didukung metode gamifikasi yang diharapkan dapat menarik mitra kerja dan dapat bermanfaat bagi banyak orang khususnya dalam bidang pendidikan dan teknologi[16][17].

\section{Literatur Terkait}

Industri Ekonomi kreatif memberikan kontribusi sebesar 7,38 persen terhadap meningkatnya perekonomian nasional Pemerintah mendukung pengembangan ekonomi kreatif dalam Inpres No. 6 Tahun 2009 yang dalam implementasinya masyarakatnya menghabiskan sebagian besar waktunya untuk menghasilkan ide yang memiliki dengan nilai tambah dari hasil kreativitas tersebut.[19].

Digitalisasi ekonomi kreatif berdampak pada terjadinya persaingan lapangan kerja, tetapi juga setiap model bisnis dari berbagai ukuran, industri, dan wilayah. Salah satu bentuk digitalisasi dalam mewujudkan sebuah ekonomi kreatif maka diperlukan sebuah e-commerce yang dapat menyediakan wadah yang mampu menampung hasil kreativitas mahasiswa dengan berbasis gamifikasi[20]. E-commerce merupakan media untuk melakukan transaksi dengan memanfaatkan internet sebagai jalur penghubung antara pembeli dan penjual tanpa harus terjadinya tatap muka secara langsung[21][22].

Manfaat dari penerapan e-commerce yaitu segala kegiatan bisnis yang dapat digunakan diakses oleh siapa dan dimana saja, dengan media komputer atau bahkan smartphone. Dengan adanya ecommerce diharapkan tidak adanya antrian dalam kegiatan jual beli[23]. Penerapan gamifikasi dalam e-commerce berguna untuk meningkatkan loyalitas pembeli dan memberikan efek termotivasi dalam melakukan transaksi dengan memanfaatkan elemen elemen dalam gamifikasi. Selain itu gamifikasi dapat dijadikan konsep pemasaran untuk menarik para customer dengan cara yang unik[24].

\section{Metode Penelitian}

Dalam penelitian ini digunakan beberapa metode penelitian diantaranya adalah identifikasi masalah, pengumpulan data, analisis, perancangan dan implementasi sistem, dan evaluasi. Ditambah dengan metode pengembangan sistem menggunakan agile yang akan menganalisis setiap percobaan yang terjadi dan dapat meminimalisir berbagai kesalahan yang terjadi. 


\section{a. 5 Tahapan penelitian sistem}

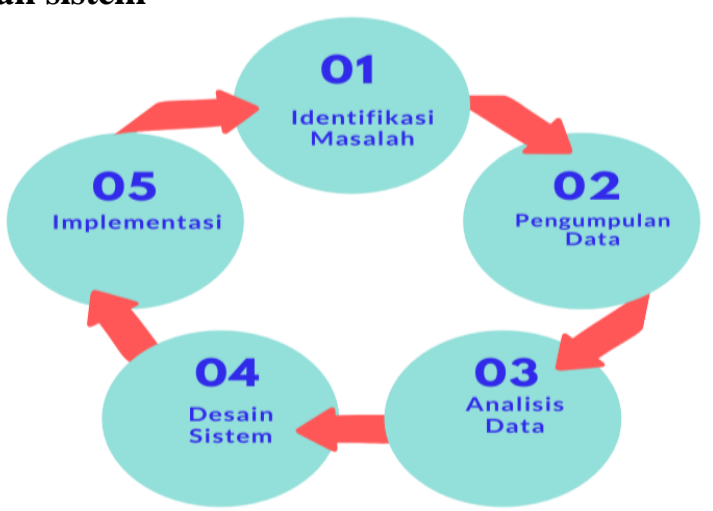

Gambar 2. Tahapan Penelitian Sistem

Dari Gambar 1 dapat diuraikan metode penelitian yang digunakan, Pertama, Metode Identifikasi Masalah, yaitu dengan mengidentifikasi masalah-masalah yang terjadi dalam perkembangan ekonomi kreatif mahasiswa dan perkembangannya[25]. Publikasi ilmiah yang kemudian dirumuskan menjadi pertanyaan yang akan dipecahkan[26]. Kedua, metode pengumpulan data yang terdiri dari observasi, yaitu observasi langsung terhadap sebuah ecommerce yang menerapkan metode gamifikasi[27]. Ketiga adalah Analisis Data, proses menganalisis data yang telah dikumpulkan dan digunakan sebagai strategi dalam membuat sistem yang lebih baik[28]. Keempat, Desain, yaitu membuat desain sistem dari data yang telah dihasilkan sebelumnya. Terakhir Implementasi Sistem yang terdiri dari perancangan prototipe sistem untuk memenuhi kebutuhan pengguna sistem[29][30]

\section{b. Pengembangan Sistem}

Proses pengembangan sistem pada penelitian ini digunakan metode agile[31]. Dimana Agile Method adalah metodologi pengembangan sistem perangkat lunak yang dalam proses pengembangannya membutuhkan waktu yang singkat untuk menyesuaikan perubahan yang terjadi [32]. Terhadap 4 hal yang perlu diperhatikan dalam metode agile diantaranya melakukan pengujian terhadap semua perubahan [33].

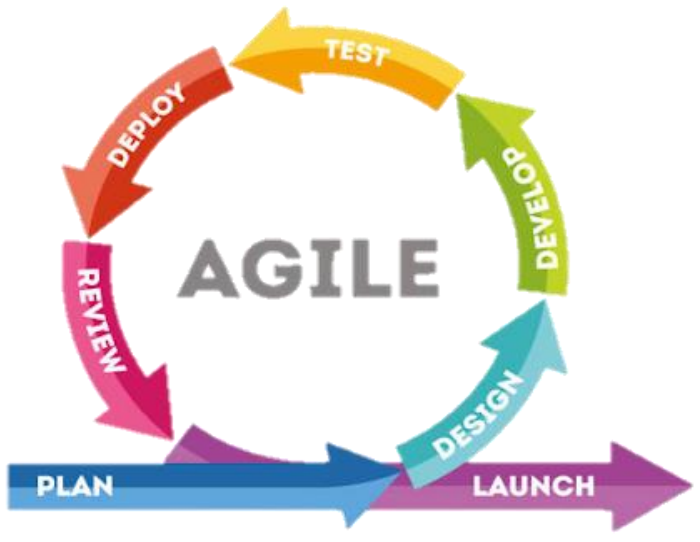

Gambar 3. Agile Method

Langkah-langkah pengembangan sistem dengan menggunakan metode agile terdiri dari perencanaan skema rencana kegiatan dan jadwal pengembangan sistem serta target yang kemudian dibuat dalam bentuk perancangan antarmuka sistem kemudian dilakukan tahapan pengembangan sistem disesuaikan dengan permintaan kustom yang telah disepakati[34]. Setelah menyelesaikan pengembangan sistem, dilakukan pengujian untuk menggunakan sistem yang telah dikembangkan secara bertahap. Hasil pengujian tersebut 
kemudian dibagikan kepada pengguna dan kemudian diperoleh tinjauan atau pembahasan hingga tahap akhir sistem diluncurkan[35]

\section{c. Metode gamifikasi dalam Sistem}

Gamifikasi adalah penggunaan teknik yang dirancang seperti permainan, untuk memotivasi / menarik seseorang yang terkait dengan penggunaannya[36]. fitur teknologi yang unik dalam gamifikasi dapat membuat pengunjung tertarik untuk ikut serta di dalamnya. Contohnya melakukan misi, mengumpulkan poin untuk mendapatkan voucher, hadiah, dan sebagainya. Kemudian ditanamkan dalam sebuah website berbasis e-commerce dengan memanfaatkan teknologi internet yang menghubungkan semua pihak untuk melakukan transaksi melalui media internet[37].

Dalam menerapkan metode gamifikasi e-commerce ini, Level Teknik Diterapkan dari berbagai teknik termasuk Badges "atau" title ", Levels, Progress bar, Leaderboards, Virtual Currency, Gifting, awarding, redeeming, trading, dimana masing-masing pengguna mendapatkan level atau rangking dari produk yang dibeli, tentunya tiap level memiliki fitur tersendiri yang membuat pengguna tertarik untuk mengupgrade tiap level.

\section{Analisis Dan Pembahasan}

Simple Random Sampling digunakan dalam penelitian ini untuk menentukan hasil survei terhadap kepercayaan pengunjung dengan situs web Pandawan. Penulis menggunakan Adapun rumus Slovin sebagai berikut :

$$
\begin{gathered}
n=\frac{N}{\left(1+N e^{2}\right)} \\
n=\frac{1567}{(1+15,60)} \\
n=\frac{1567}{16,60} \\
n=94,40 \% \text { (dibulatkan ke 94 Responden) }
\end{gathered}
$$

Dari rumus sampling populasi total populasi ( $\mathrm{N}=1567$ responden) menghasilkan sampel minimal 94 responden yang mengingat metode ini. Setelah mendapatkan hasil survey dari rumus Slovin, selanjutnya dilakukan pengujian reliabilitas dengan Cronbach alpha sebagai berikut:

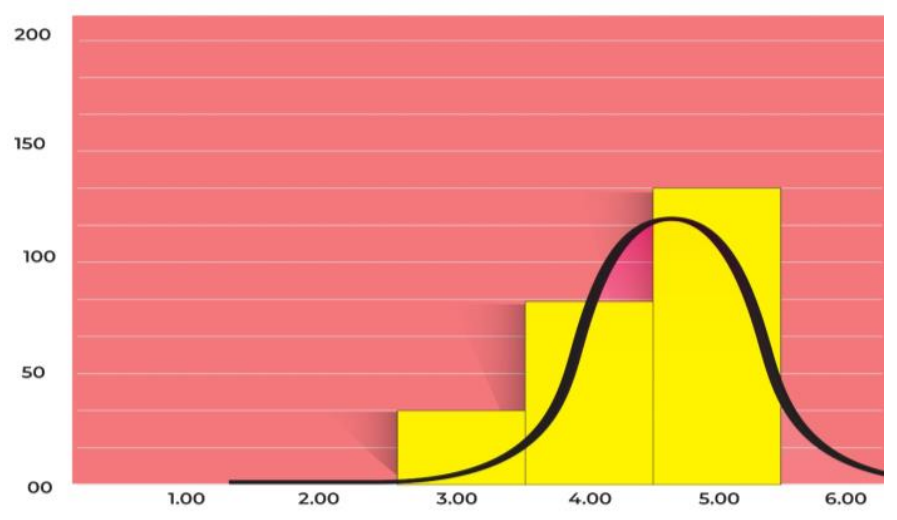

Gambar 4. Histogram Cronbach Alpha

Berdasarkan gambar 3 (tiga), Histogram chart memiliki mean 4,58, dengan deviasi 0, 63 dari 210 responden. Proses kasus dapat dijelaskan pada tabel berikut. 
Tabel Kasus data

\begin{tabular}{|lr|l|l|}
\hline & & $\mathrm{N}$ & $1 . \%$ \\
\hline Kasus & & 210 & 100,0 \\
Hari & 0 & 0 \\
& $\begin{array}{r}\text { Kecuali } \\
\text { Jumlah }\end{array}$ & 210 & 100,0 \\
\hline
\end{tabular}

Tabel 2. Keandalan Statistik

\begin{tabular}{|c|c|}
\hline Cronbach Alpha & N Item \\
\hline 0,925 & 25 \\
\hline
\end{tabular}

\section{Kesimpulan}

Makalah ini menjelaskan penelitian tentang platform e-commerce yang menyediakan layanan penerbit jurnal dengan metode gamification untuk mendukung dunia ekonomi kreatif yang dapat memberikan kontribusi besar bagi peningkatan perekonomian nasional. Masih sangat sedikit platform e-commerce khusus yang menyediakan layanan pengelolaan jurnal berbasis online dengan harga bersaing. Menjadi transformasi baru yang awalnya konvensional ke digitalisasi. Dalam pandangan penulis, platform e-commerce berbasis gamification memberikan kemudahan bagi institusi pendidikan yang mengalami kesulitan dalam menerbitkan jurnal.

Dalam pembahasan penelitian ini, penulis belum dapat menentukan elemen gamification yang paling tepat digunakan pada platform e-commerce yang memberikan layanan penerbit jurnal dan kemampuannya untuk bersaing dalam dunia ekonomi kreatif secara global. Terlepas dari kekurangan tersebut aplikasi gamification dapat dijadikan nilai lebih untuk memasarkan platform tersebut ke pasar global dengan konsep memasukkan elemen-elemen game ke dalam platform non-game. Penulis tidak dapat mengklaim bahwa gamifikasi adalah cara yang paling tepat, tetapi dapat digunakan sebagai acuan dalam penelitian selanjutnya.

Penerapan gamification pada e-commerce saat ini tidak berhenti hanya untuk kebutuhan penelitian. Namun sebaliknya, langkah selanjutnya yang dapat dilakukan adalah melakukan penyesuaian dan evaluasi mengenai elemen gamifikasi mana yang paling cocok untuk diterapkan pada website e-commerce ditinjau dari kebutuhan penggunanya yang diharapkan dapat meningkatkan loyalitas pengguna dalam transaksi.

\section{Ucapan Terima Kasih}

Penelitian Implementasi oleh BRIN Ristek dalam program Penelitian Dosen Pemula (PDP) 2019-2020. Terima kasih kepada Universitas Raharja dan Alphabet Incubator yang telah memfasilitasi dalam proses pengumpulan data. Serta untuk para pembaca penulis mengucapkan terima kasih semoga dapat bermanfaat.

\section{Daftar Pustaka}

[1] R. Gouvea and G. Vora, "Creative industries and economic growth: stability of creative products exports earnings," Creat. Ind. J., vol. 11, no. 1, pp. 22-53, 2018. 
[2] U. Rahardja, Q. Aini, Y. I. Graha, and M. R. Tangkaw, "Gamification Framework Design of Management Education and Development in Industrial Revolution 4.0," J. Phys. Conf. Ser., vol. 1364, no. 1, pp. 0-13, 2019, doi: 10.1088/1742-6596/1364/1/012035.

[3] M. Dunska and A. Marcinkevica, "Situation and development opportunities of creative industries companies in Latvia," 2017.

[4] D. R. Rahadi, "Analisis Sektor Usaha Kecil \& Menengah Menjadi Model Kewirausahaan Sosial Berbasis Ekonomi Kreatif," FIRM J. Manag. Stud., vol. 3, no. 1, pp. 16-31, 2018.

[5] M. Prawira, H. T. Sukmana, V. Amrizal, and U. Rahardja, "A Prototype of AndroidBased Emergency Management Application,” 2019 7th Int. Conf. Cyber IT Serv. Manag. CITSM 2019, 2019, doi: 10.1109/CITSM47753.2019.8965337.

[6] A. T. Syauqi, "Startup sebagai Digitalisasi Ekonomi dan Dampaknya bagi Ekonomi Kreatif di Indonesia," Univ. Gadjah Mada-Yogyakarta, Indones., 2016.

[7] T. Hariguna, U. Rahardja, Q. Aini, and Nurfaizah, "Effect of social media activities to determinants public participate intention of e-government," Procedia Comput. Sci., vol. 161, pp. 233-241, 2019, doi: 10.1016/j.procs.2019.11.119.

[8] Sudaryono, U. Rahardja, and E. P. Harahap, "Implementation of Information Planning and Strategies Industrial Technology 4.0 to Improve Business Intelligence Performance on Official Site APTISI," J. Phys. Conf. Ser., vol. 1179, no. 1, pp. 0-7, 2019, doi: 10.1088/1742-6596/1179/1/012111.

[9] M. Hamsani and M. Khairiyansyah, "The Opportunity of SMEs Development by Triple Helix ABG Method in Supporting Creative Economy in Pangkalpinang City," Integr. J. Bus. Econ., vol. 2, no. 1, pp. 76-83, 2018.

[10] A. R. R. T. Hidayat and A. Y. Asmara, "Creative industry in supporting economy growth in Indonesia: Perspective of regional innovation system," in IOP Conference Series: Earth and Environmental Science, 2017, vol. 70, no. 1, p. 12031.

[11] Q. Aini, U. Rahardja, and T. Hariguna, "The antecedent of perceived value to determine of student continuance intention and student participate adoption of ilearning," Procedia Comput. Sci., vol. 161, pp. 242-249, 2019, doi: 10.1016/j.procs.2019.11.120.

[12] F. N. Khasanah, S. Rofiah, and D. Setiyadi, "Metode User Centered Design Dalam Merancang Tampilan Antarmuka Ecommerce Penjualan Pupuk Berbasis Website Menggunakan Aplikasi Balsamiq Mockups,” JAST, vol. 3, no. 2, pp. 14-23, 2019.

[13] U. Rahardja, Q. Aini, M. Yusup, and A. Edliyanti, "Penerapan Teknologi Blockchain Sebagai Media Pengamanan Proses Transaksi E-Commerce," Comput. Eng. Sci. Syst. J., vol. 5, no. 1, pp. 28-32.

[14] U. Rahardja, T. Hariguna, and Q. Aini, "Understanding the impact of determinants in game learning acceptance: An empirical study," Int. J. Educ. Pract., vol. 7, no. 3, pp. 136-145, 2019, doi: 10.18488/journal.61.2019.73.136.145.

[15] C. McNair, "Worldwide retail and ecommerce sales: emarketer's updated forecast and new mcommerce estimates for 2016-2021," Ind. Report, eMarketing, 2018.

[16] A. S. Hussein, N. H. Rosita, and R. F. Ayuni, "Knowledge management orientation 
behaviour and innovation: A lesson from Indonesia creative economy sector," Int. J. Sociotechnology Knowl. Dev., vol. 11, no. 1, pp. 17-28, 2019.

[17] Sudaryono, U. Rahardja, Q. Aini, Y. Isma Graha, and N. Lutfiani, "Validity of Test Instruments," J. Phys. Conf. Ser., vol. 1364, no. 1, 2019, doi: 10.1088/17426596/1364/1/012050.

[18] B. E. Kreatif, "Data Statistik dan Hasil Survei Ekonomi Kreatif," Kerjasama Badan Ekon. Kreat. dan Badan Pus. Stat., 2017.

[19] A. Masri, "Pendekatan Desain Bagi Industri Kerajinan Kreatif Sebuah Usulan Bagi Program Implementasi Ekonomi Kreatif Di SektorIndustri Kerajinan Indonesia," -, 2010.

[20] K. Wardani, "Pengaruh Kemandirian Belajar Terhadap Kreativitas Belajar Dalam Kaitannya Dengan Prestasi Belajar IPS Siswa Kelas VII SMP Muhammadiyah 1 Metro Tahun Pelajaran 2016/2017.” Magister Pendidikan Ilmu Pengetahuan Sosial, 2017.

[21] U. Rahardja, T. Hariguna, and W. M. Baihaqi, "Opinion mining on e-commerce data using sentiment analysis and k-medoid clustering," Proc. - 2019 12th Int. Conf. UbiMedia Comput. Ubi-Media 2019, pp. 168-170, 2019, doi: 10.1109/UbiMedia.2019.00040.

[22] Q. Aini, M. Budiarto, P. O. Hadi Putra, A. Khoirunisa, N. P. L. Santoso, and U. Rahardja, "Gamified education practice: Designing with e-commerce and ilearning concept," Int. J. Psychosoc. Rehabil., vol. 24, no. 7, 2020, doi: 10.37200/IJPR/V24I7/PR270799.

[23] Q. Aini, T. Hariguna, P. O. H. Putra, and U. Rahardja, "Understanding how gamification influences behaviour in education," Int. J. Adv. Trends Comput. Sci. Eng., vol. 8, no. 1.5 Special Issue, pp. 269-274, 2019, doi: 10.30534/ijatcse/2019/4781.52019.

[24] Q. Aini, S. Riza Bob, N. P. L. Santoso, A. Faturahman, and U. Rahardja, "Digitalization of Smart Student Assessment Quality in Era 4.0," Int. J. Adv. Trends Comput. Sci. Eng., vol. 9, no. 1.2, pp. 257-265, Apr. 2020, doi: 10.30534/ijatcse/2020/3891.22020.

[25] Sudaryono, U. Rahardja, and Masaeni, "Decision Support System for Ranking of Students in Learning Management System (LMS) Activities using Analytical Hierarchy Process (AHP) Method," J. Phys. Conf. Ser., vol. 1477, no. 2, 2020, doi: 10.1088/17426596/1477/2/022022.

[26] Y. Yang, Y. Asaad, and Y. Dwivedi, "Examining the impact of gamification on intention of engagement and brand attitude in the marketing context," Comput. Human Behav., vol. 73, pp. 459-469, 2017.

[27] I. Handayani, U. Rahardja, E. Febriyanto, H. Yulius, and Q. Aini, "Longer Time Frame Concept for Foreign Exchange Trading Indicator using Matrix Correlation Technique," Proc. 2019 4th Int. Conf. Informatics Comput. ICIC 2019, 2019, doi: 10.1109/ICIC47613.2019.8985709.

[28] K. Huotari and J. Hamari, "A definition for gamification: anchoring gamification in the service marketing literature," Electron. Mark., vol. 27, no. 1, pp. 21-31, 2017.

[29] N. F. Rozy, R. Ramadhiansya, P. A. Sunarya, and U. Rahardja, "Performance Comparison Routing Protocol AODV, DSDV, and AOMDV with Video Streaming in 
Manet," 2019 7th Int. Conf. Cyber IT Serv. Manag. CITSM 2019, 2019, doi: 10.1109/CITSM47753.2019.8965386.

[30] P. A. Sunarya, U. Rahardja, and D. I. Desrianti, "Development Assessment Module Portfolio E-Imei Students With Learning To Improve The Quality Of Concentration Case Study Mavib," vol. 13, no. 8, pp. 3597-3606, 2016.

[31] H. Tussifah, "Strategi bersaing dengan agile manufacturing," Al Tijarah, vol. 3, no. 1, pp. 15-28, 2017.

[32] K. Curcio, T. Navarro, A. Malucelli, and S. Reinehr, "Requirements engineering: A systematic mapping study in agile software development," J. Syst. Softw., vol. 139, pp. 32-50, 2018.

[33] T. Dingsøyr, N. B. Moe, T. E. Fægri, and E. A. Seim, "Exploring software development at the very large-scale: a revelatory case study and research agenda for agile method adaptation,” Empir. Softw. Eng., vol. 23, no. 1, pp. 490-520, 2018.

[34] Sudaryono, N. Lutfiani, Suseno, and Q. Aini, "Empirical Study of Research Performance Leading to Education 4.0 using the iLearning Method," Int. J. Adv. Trends Comput. Sci. Eng., vol. 8, no. 1.5, pp. 264-268, Nov. 2019, doi: 10.30534/ijatcse/2019/4681.52019.

[35] Y. Korobov, "Impact of digitalization on consumer behaviour and marketing activity in financial markets," in SHS Web of Conferences, 2020, vol. 73, p. 1013.

[36] Q. Aini, U. Rahardja, I. Handayani, M. Hardini, and A. Ali, "Utilization of google spreadsheets as activity information media at the official site alphabet incubator," Proc. Int. Conf. Ind. Eng. Oper. Manag., no. 7, pp. 1330-1341, 2019.

[37] U. Rahardja, A. Moeins, and N. Lutfiani, "Leadership, competency, working motivation and performance of high private education lecturer with institution accreditation B: Area kopertis IV Banten province," Man India, vol. 97, no. 24, pp. 179-192, 2017. 